\title{
Guidelines to Incorporate a Clinician User Experience (UX) into the Design of Patient-Operated mHealth
}

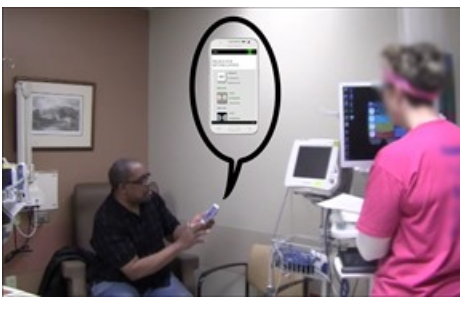

Figure 1: A clinician (study participant) performing medication reconciliation during a simulation with a role-player who is using a patient-operated mHealth prototype to accurately share medication details. When the prototype was not used, study participants were not able to achieve the same level of

accuracy regarding medication information.

\section{Harry Tunnell}

Indiana University School of

Informatics and Computing

Indianapolis, IN 46202, USA

hadtunne@iupui.edu

\section{Anthony Faiola}

University of Illinois at Chicago

Biomedical \& Health Information

Sciences

Chicago, IL, 60607, USA

faiola@uic.edu

\section{Davide Bolchini}

Indiana University School of

Informatics and Computing

Indianapolis, IN 46202, USA

dbolchin@iupui.edu

Permission to make digital or hard copies of part or all of this work for personal or classroom use is granted without fee provided that copies are not made or distributed for profit or commercial advantage and that copies bear this notice and the full citation on the first page. Copyrights for third-party components of this work must be honored. For all other uses, contact the Owner/Author. Copyright is held by the owner/author(s).

CHI'17 Extended Abstracts, May 06-11, 2017, Denver, CO, USA ACM 978-1-4503-4656-6/17/05.

http://dx.doi.org/10.1145/3027063.3052966

\begin{abstract}
This interactivity demonstration paper highlights how a patient-operated mHealth solution can be designed to improve clinician understanding of a patient's health status during a first face-to-face encounter. Patients can use smartphones to retrieve difficult-to-recall-from memory personal health information. This provides an opportunity to improve patient-clinician collaboration. To explore this idea, a mixed method study with 12 clinicians in a simulated encounter was conducted. A smartphone personal health record was prototyped and used for an experimental study. Communication, efficiency, and effectiveness was improved for clinicians who experienced the prototype. Study outcomes included a validated set of design guidelines for mHealth tools to support better patient-clinician communication.
\end{abstract}

\section{Author Keywords}

Design guidelines; secondary user experience (UX); health information technology (HIT); personal health record (PHR); mHealth.

\section{ACM Classification Keywords}

H.5.2. Information interfaces and presentation (e.g., HCI): User interfaces; J.3. Computer applications: Life and medical sciences. 


\section{Experimental Study}

A mixed method study, consisting of 12 simulated (first) face-to-face clinical encounters was conducted (Figure 1), in which: (1) an actor role-played a patient and (2) experienced doctors and nurses were the study participants. The design included a post-test-only control group, with randomization and matching to ensure a similar number of doctors were assigned to the control and treatment groups [1]. The presence of the prototype was the treatment. All simulations were video recorded for analysis. Study participants completed a post-test questionnaire and interview. Prototype use improved communication within the dyad for most tasks in the treatment group when compared to the control group. Efficiency and effectiveness of collaboration for secondary users with the primary user was also better in the treatment group.

\section{Introduction}

This interactivity demonstration paper describes design guidelines for a mobile health information technology (mHealth) that is used to improve face-to-face collaboration between a primary user (patient) and secondary user (clinician). Clinical tasks, such as medication reconciliation, improve patient care but are difficult to complete because patients often forget details or clinicians are pressed for time [2]. The patient-operated mHealth (presented here) is designed to augment patient recall and increase clinician efficiency, with the potential to improve the conduct of a clinical encounter.

Human-computer interaction ( $\mathrm{HCI}$ ) user modeling identifies secondary users as people who are affected by the main or primary user's operation of a technology [3-5]. Primary users are the dominate operators that control the system and the dissemination of its information [3]. Even though secondary users have been identified in the medical informatics literature, they are often operationalized as patients. However, patient-operated mHealth means that clinicians are potential secondary users. We performed research that resulted in design guidelines that consider both the primary and secondary user experience (UX).

\section{Background and Related Work}

Even though interest in secondary users is increasing, those most often researched are primary users, while investigations about secondary users are limited [6]. There is also a lack of a theory in the HCI literature to explain why secondary users are relevant and how they should be considered in technology design. Common ground, a theory about language use can help fill this void. Common ground is established when people have particular knowledge in common, while also knowing that they have such common knowledge [7]. Research suggests that well-designed collaborative technologies speed up the development of common ground by allowing teams to share knowledge, manage actions, and make decisions efficiently [8]. While improving patient access to health information leads to increased patient participation in health-related decision-making, it is not merely the access to data that creates this outcome [9]. It is the development of common ground between patients and clinicians that makes superior patient engagement possible.

An experimental study was used to investigate the idea that patient-operated mHealth can be designed to improve how common ground is created during a first face-to-face clinical encounter. After the experimental study, the research data was evaluated and the preliminary design guidelines (created during formative work) were revised into a final set of design guidelines. The design guidelines emphasize the creation of common ground in the patient-clinician communication. The experiment validated the guidelines and the notion of using mHealth to improve common ground.

\section{Design Guidelines}

To be effective, the guidelines should lead to designs that do not disrupt patient or clinician workflow [10]. Primary users share information by verbalizing content or sharing the interface with secondary users.

\begin{tabular}{lll}
\hline No. & Guideline & Example \\
\hline 1 & $\begin{array}{l}\text { Identify primary and } \\
\text { secondary user } \\
\text { goals with the } \\
\text { system. }\end{array}$ & $\begin{array}{l}\text { Patients consume } \\
\text { information with lay } \\
\text { language. Clinicians } \\
\text { require clinical context. }\end{array}$ \\
\hline
\end{tabular}




\section{Formative Work}

Before the experimental study could be conducted, formative work was required to create the prototype (Figure 2), which was a smartphone personal health record (PHR) prototype. A

PHR is patient-operated mHealth that a person uses to manage their personal health information.

The design guidelines were created as part of the formative work, which occurred sequentially in four parts. First, a pilot study was conducted to test and validate the tools used for data collection and prototyping. Second, patients and clinicians were interviewed. Third, online survey questionnaires were used to validate and extend what had already been learned. Fourth, the guidelines were written and the prototype created. Usability testing was performed with patients and clinicians.

\section{2}

Expect primary user
interactions with the
system to affect the
system to affect the

secondary user.

3 Assume that primary and secondary users have different experiences, but do not ignore the idea that some will be similar or overlap.

6 Primary and secondary users may each hold the device differently, as such, features and functions should anticipate how each receives and manipulates the device.

7 The system provides feedback to secondary users that removes irrelevant and overly complex information without degrading the primary UX.

8 Incorporate

language and representation tailored to secondary users without degrading the experience of the primary user.

\section{Example}

The patient retrieves data from the PHR and configures the interface for the clinician.

Some information is not complex or difficult to recall and does not require much reorganization before sharing.

Each may manipulate similar data differently. A clinician may want to expand the view of an injury to see more detail. The patient just wants to check that the image was captured and stored in the PHR.

Clinicians do not need the full access to data that patients may require. Patients need to enter and update data in the PHR while clinicians do not.

The different decisions required from patients and clinicians require different information (this includes how the same data about a single issue might be organized differently for each class of user).

\begin{tabular}{|c|c|c|}
\hline No. & Guideline & Example \\
\hline 9 & $\begin{array}{l}\text { Plan for and perform } \\
\text { usability evaluations } \\
\text { with secondary } \\
\text { users. }\end{array}$ & $\begin{array}{l}\text { Recruit participants so } \\
\text { both classes of user are } \\
\text { represented. }\end{array}$ \\
\hline 10 & $\begin{array}{l}\text { Consider how to } \\
\text { incorporate design } \\
\text { elements that can } \\
\text { be perceived from a } \\
\text { distance to improve } \\
\text { secondary user } \\
\text { interaction with the } \\
\text { device. }\end{array}$ & $\begin{array}{l}\text { Secondary user screens } \\
\text { may need to use a } \\
\text { different font color } \\
\text { and/or size to enhance } \\
\text { visibility from a } \\
\text { distance. }\end{array}$ \\
\hline 11 & $\begin{array}{l}\text { Some information } \\
\text { incorporated for the } \\
\text { secondary user will } \\
\text { be irrelevant for the } \\
\text { primary user, but } \\
\text { the primary user will } \\
\text { still have to know } \\
\text { how to configure it } \\
\text { for the secondary } \\
\text { user. }\end{array}$ & $\begin{array}{l}\text { Clinicians use review of } \\
\text { systems to evaluate } \\
\text { patient problems. A } \\
\text { patient must know how } \\
\text { to reach this type of } \\
\text { information even } \\
\text { though patients do not } \\
\text { use review of systems } \\
\text { as an organizing and } \\
\text { evaluation tool. }\end{array}$ \\
\hline
\end{tabular}

\section{Conclusion}

This research and the resulting guidelines are among the first exemplars to recognize that secondary UXs are task dependent and that patient-operated mHealth can be used to improve common ground in the patientclinician encounter. The prototype design protected the clinician's workflow. This contributed to the shorter overall mean time for encounters and greater efficiency in terms of attention paid to each task (i.e., those observed during the experimental study).

In healthcare settings, when primary and secondary users have different levels of knowledge (the patient as layperson and the clinician as expert), a well-designed 


\section{Different Classes of User}

It is our contention that primary and secondary users should be considered two distinct classes of user, rather than viewing secondary users as an extension of primary users. This ensures that secondary user goals with a product, system, or service will be distinctly evaluated and considered. It also ensures that the different perspectives on similar information will be examined as well as how information should be manipulated to create a framework for common ground between primary and secondary users. digital artifact can bridge the chasm of understanding This may, however, require compromises from a traditional usability perspective. For example, a primary user may have to navigate through parts of the interface without understanding the information as they configure it for the secondary user. The primary user still needs to understand context (e.g., problem description) so s/he can navigate correctly. Conversely, $\mathrm{s} /$ he does not need to understand details in the secondary user's interface (e.g., review of systems). This is because it is an expert level knowledge.
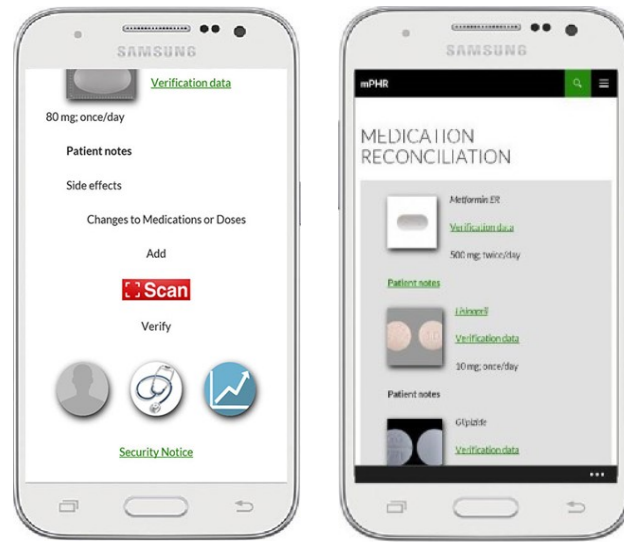

Figure 2: Primary user (left) and secondary user (right) medication screens. The icons on the primary user screen are used to switch between different views of similar information.

The design guidelines provide a tool to evaluate UXs in the primary and secondary user context. They also provide a framework by which to make decisions about how these diverse information needs for each class of user should manifest in an interface. This is a novel aspect of the research and an important contribution to the HCI literature.

\section{References}

1. Babbie, E., The basics of social research. 5th ed. 2011, Belmont, CA: Cengage Learning.

2. Lee, K.P., et al., "Whose job is it, really?" Physicians', nurses', and pharmacists' perspectives on completing inpatient medication reconciliation. Journal of Hospital Medicine, 2015. 10(3): p. 184-186.

3. Eason, K., Information technology and organizational change. 1988, New York, NY: Taylor \& Francis.

4. Alsos, O.A. and D. Svanæs, Designing for the secondary user experience, in INTERACT 2011, P. Campos, et al., Editors. 2011, Springer-Verlag: New York. p. 84-91.

5. Abras, C., D. Maloney-Krichmar, and J. Preece, Usercentered design, in Encyclopedia of Human-Computer Interaction, W. Bainbridge, Editor. 2004, Sage Publications: Thousand Oaks. p. 445-56.

6. Ferneley, E. and B. Light, Secondary user relations in emerging mobile computing environments. European Journal of Information Systems, 2006. 15(3): p. 301306.

7. Kellogg, W.A., et al., Leveraging digital backchannels to enhance user experience in electronically mediated communication, in 20th Anniversary Conference on Computer Supported Cooperative Work. 2006, ACM: Banff, Alberta, Canada. p. 451-454.

8. Convertino, G. and J.M. Carroll, Toward experimental methods in collaborative computing research, in The handbook of emergent technologies in social research S.N. Hesse-Biber, Editor. 2011, Oxford University Press: Oxford, UK. p. 342-368.

9. Prey, J.E., et al., Patient engagement in the inpatient setting: A systematic review. 2014. 21(4): p. 742750.

10. Chen, Y., et al., The invisible work of health providers. Interactions, 2014. 21(5): p. 74-77. 